\title{
7 \\ How, when and why did fertility decline?
}

This chapter uses both bivariate and multivariate methods of analysis to examine whether the historical fertility decline in Tasmania was due to changes in starting, stopping and/or spacing behaviours. These analyses also provide answers to the questions of when fertility fell and why it fell at this time; specifically, how the findings support theories of the historical fertility decline outlined in Chapter 1. In the analysis that follows, measures of starting, stopping and spacing behaviours are based on pregnancies that resulted in a live birth rather than live births, because of the occurrence of twin births in the population.

\section{Bivariate analysis}

\section{Starting}

As discussed in Chapter 1, scholars have argued that couples did not deliberately control their fertility through marrying earlier or laterthat is, starting behaviour was not an individual form of fertility control. Instead, the timing of marriage related to economic, social and psychological factors, not to fertility preferences (McDonald 1981). This argument is supported by findings from studies of marriage in pretransitional and transitional societies in Western Europe and Asia (Lundh and Kurosu 2014). 
Age at marriage for women rose from the $1860 / 70$ cohorts to the 1890 cohort, from a mean of 21.8 years (median 21.2) in the $1860 / 70$ cohorts to a mean of 23.1 years (median 22.3) in the 1890 cohort (Table 7.1). The proportion of women who married as teenagers fell steadily, from 36.7 per cent in the $1860 / 70$ cohorts to 21.4 per cent in the 1890 cohort. By 1890, just over one-quarter of women were aged 25 years or older when they married. As noted previously, the increase in the age at marriage for women may be partly due to the increase in the ratio of females to males of marriageable age that occurred over the period.

Table 7.1 Age at marriage for women with children in their first marriage, complete group: 1860/70, 1880 and 1890 marriage cohorts, Tasmania

\begin{tabular}{|l|r|r|r|}
\hline Marriage cohort & $1860 / 70$ & \multicolumn{3}{|c|}{1880} & \multicolumn{1}{|c|}{1890} \\
\hline Age at marriage & \multicolumn{3}{|c|}{ Percentage } \\
\hline$<20$ years & 36.7 & 30.5 & 21.4 \\
\hline 20 to $<25$ years & 45.1 & 53.0 & 50.1 \\
\hline $25+$ years & 18.2 & 15.8 & 27.6 \\
\hline Missing & 0.0 & 0.7 & 0.9 \\
\hline Total (\%) & 100.0 & 100.0 & 100.0 \\
\hline Total (no.) & 539 & 417 & 529 \\
\hline Mean/median & \multicolumn{3}{|c}{ Age at marriage } \\
\hline Mean & 21.8 & 22.0 & 23.1 \\
\hline Median & 21.2 & 21.2 & 22.3 \\
\hline
\end{tabular}

Note: Means and medians exclude missing data.

Consistent with trends in age at marriage, age at first birth also increased over the marriage cohorts, from a mean age of 23.2 years (median 22.3) in the $1860 / 70$ cohorts to a mean of 24.3 years (median 23.4) in the 1890 cohort (Table 7.2). The proportion of women having their first birth as a teenager fell markedly, from 23.8 per cent in the $1860 / 70$ cohorts to 14.6 per cent in the 1890 cohort. In all four marriage cohorts, only a small proportion of women had their first birth at 30 years or older. 
Table 7.2 Age at first birth, complete group: 1860/70, 1880 and 1890 marriage cohorts, Tasmania

\begin{tabular}{|l|r|r|r|}
\hline Marriage cohort & $1860 / 70$ & 1880 & \multicolumn{1}{|c|}{1890} \\
\hline Age at marriage & \multicolumn{3}{|c|}{ Percentage } \\
\hline$<20$ years & 23.8 & 18.0 & 14.6 \\
\hline 20-24 years & 48.4 & 57.1 & 48.0 \\
\hline 25-29 years & 19.5 & 17.0 & 25.5 \\
\hline 30+ years & 8.3 & 7.2 & 11.0 \\
\hline Missing & 0.0 & 0.7 & 0.9 \\
\hline Total (\%) & 100.0 & 100.0 & 100.0 \\
\hline Total (no.) & 539 & 417 & 529 \\
\hline Mean/median & Age at first birth \\
\hline Mean & 23.2 & 23.1 & 24.3 \\
\hline Median & 22.3 & 22.2 & 23.4 \\
\hline
\end{tabular}

Note: Means and medians exclude missing data.

\section{Measures of stopping and spacing}

As discussed in Chapter 1, there are differing views among scholars as to the extent to which couples reduced their fertility through practising stopping and/or spacing behaviours. Part of this controversy involves the methods that have been used to identify stopping and spacing behaviours. A critical review of these methods can be found in Van Bavel (2004b).

I did not construct age-specific marital fertility rates for the complete group in the four marriage cohorts, since these women were not representative of all married women in Tasmania at that time and their age-specific fertility rates would not be comparable with the age-specific marital fertility rates of any other population. Thus, methods used to identify stopping and/ or spacing using fertility rates by age, such as Coale and Trussell's (1974, 1978 ) indices $M$ and $m$ and Ewbank's (1989) indices of marital fertility, are not discussed here.

The mean age of mother at last birth is one of the simplest indicators of stopping behaviour (Knodel 1987; Gutmann and Alter 1993). If the mean age of the mother at the birth of the last child falls, families are assumed to be practising stopping behaviour. 
For women in the Tasmanian marriage cohorts, mean age at last birth fell steadily from the $1860 / 70$ cohorts to the 1890 cohort, from 38.8 years (median 40) to 36.1 years (median 37) (Table 7.3). The proportion who had their last birth when they were under 30 years of age increased from 8.7 per cent to 19.7 per cent for the $1860 / 70$ cohorts to the 1890 cohort, while the proportion who were 40 years or older fell from 51.2 per cent to 29.7 per cent.

Table 7.3 Age at last birth, complete group: 1860/70, 1880 and 1890 marriage cohorts, Tasmania

\begin{tabular}{|l|r|r|r|}
\hline Marriage cohort & $1860 / 70$ & \multicolumn{3}{|c|}{1880} & 1890 \\
\hline Age at last birth & \multicolumn{3}{|c|}{ Per cent } \\
\hline$<30$ years & 8.7 & 13.9 & 19.7 \\
\hline 30-34 years & 11.3 & 13.4 & 16.3 \\
\hline 35-39 years & 28.8 & 32.1 & 33.5 \\
\hline 40+ years & 51.2 & 39.8 & 29.7 \\
\hline Missing & 0.0 & 0.7 & 0.9 \\
\hline Total (\%) & 100.0 & 100.0 & 100.0 \\
\hline Total (no.) & 539 & 417 & 529 \\
\hline Mean/median & Age at last birth \\
\hline Mean & 38.8 & 37.5 & 36.1 \\
\hline Median & 40.0 & 38.5 & 37.0 \\
\hline
\end{tabular}

Note: Means and medians exclude missing data.

Some scholars consider mean age at last birth a problematic indicator, since it can be affected by spacing behaviour as well as stopping behaviour (Anderton 1989). Anderton (1989) argues that if families space their births and the onset of sterility does not change, mean age at last birth will fall, because with longer birth spacing the onset of sterility will occur before families can have the next 'spaced' birth. Thus, spacing behaviour also increases the open interval — that is, the period between the last birth and the onset of sterility. Knodel and McDonald (Knodel 1987; McDonald and Knodel 1989) acknowledge that spacing behaviour can affect the mean age at last birth in the way described but argue that spacing has only a modest impact on this indicator. They estimated that a period of, at most, half the increase in the last closed birth interval can be attributed to spacing behaviour when analysing the fall in the mean age at last birth. Thus, if the last closed interval increases by four months, only two months 
of the decrease in the mean age at last birth can be attributed to spacing behaviour, with the rest attributed to stopping behaviour (Knodel 1987; Okun 1995).

Okun (1995) used Barrett's Monte Carlo microsimulation model of the reproductive process to investigate the extent to which mean age at last birth was affected by stopping and spacing behaviours. She simulated the birth histories of women with various levels of fecundability, who either adopted no fertility control or practised stopping or spacing behaviours with different degrees of success. In her simulation, she found that small reductions in mean age at last birth could not necessarily be attributed to stopping behaviour, since spacing behaviour that was practised continuously through marriage had a greater impact on mean age at last birth than McDonald and Knodel (1989) claimed.

Based on her simulation results, Okun concludes that examining changes in the mean age at last birth according to age at marriage is a more useful way of distinguishing 'stopping' from 'spacing' behaviour than looking at changes in mean age at last birth overall. This is because when couples do not control their fertility, age at marriage does not have any relationship with age at last birth. However, when couples practise stopping behaviour, women who marry at younger ages stop their childbearing earlier (McDonald 1984).

Examining mean age at last birth by age at marriage for the Tasmanian marriage cohorts shows the fall in mean age at last birth was somewhat higher for women marrying under 25 years of age than for women marrying at 25 years or older (Table 7.4). For women marrying under 20 years of age, mean age at last birth was 38.3 years (median 40.4 ) in the $1860 / 70$ cohorts and fell to 35.5 years (median 37) in the 1890 cohort. The fall in the mean age at last birth, however, was not as large for those marrying at 25 years or older, with mean age at last birth falling from 39.3 years (median 39.9) to 37.7 years (median 38) from the $1860 / 70$ to the 1890 cohorts. The proportion of women completing their childbearing before age 35 years increased markedly for those marrying under 25 years of age, from around 20 per cent of women in the 1860/70 cohorts to around 40 per cent in the 1890 cohorts (Appendix A: Table A.20). Corresponding proportions for those marrying at age 25 years or older were 17.4 per cent and 24 per cent. Therefore, in the Tasmanian marriage cohorts, age at marriage was related to age at last birth, which is consistent with the practice of stopping behaviour. 
Table 7.4 Mean (median) age at last birth by age at marriage, complete group: 1860/70, 1880 and 1890 marriage cohorts, Tasmania

\begin{tabular}{|l|r|r|r|}
\hline Marriage cohort & $1860 / 70$ & \multicolumn{1}{|c|}{1880} & \multicolumn{1}{|c|}{1890} \\
\hline Age at marriage & \multicolumn{3}{|c|}{ Mean age at last birth } \\
\hline$<20$ years & 38.3 & 36.6 & 35.5 \\
\hline Mean & 40.4 & 37.2 & 37.0 \\
\hline Median & 38.7 & 37.5 & 35.4 \\
\hline 20-24 years & 39.8 & 38.4 & 36.2 \\
\hline Mean & \multicolumn{3}{|l}{} \\
\hline Median & 39.3 & 36.6 & 37.7 \\
\hline 25+ years & 39.9 & 39.4 & 38.0 \\
\hline Mean &
\end{tabular}

Note: Excludes three women in the 1880 cohort and five in the 1890 cohort for whom age was missing.

Measures to detect deliberate spacing behaviour are difficult to find (Knodel 1987). In populations with natural fertility, birth intervals can vary markedly because of differences in breastfeeding practices, periodic separation of spouses or factors beyond the couple's control, such as levels of fecundity and intrauterine mortality. Birth intervals that increase with parity do not necessarily mean that couples are practising parity-dependent birth spacing, since birth intervals may increase as women age because of decreasing fecundity or decreased sexual activity. Last birth intervals are thus longer than other birth intervals. Also, very long last birth intervals do not necessarily imply that couples are deliberately spacing their births, as they may reflect failed attempts to stop childbearing. Couples who decide to stop having children, for instance, may have another birth accidently or may have stopped childbearing but decide to have another birth after one of their children dies.

In the Tasmanian marriage cohorts, the mean (median) interval between marriage and first birth was longer for women in the 1860/70 cohorts than for women in the other two cohorts, with a mean of 17 months (median 11.2) for the $1860 / 70$ cohorts compared with 12.9 months (median 10.3) for the 1880 cohort and 15 months (median 10.9) for the 1890 cohort (Table 7.5). This may partly reflect the higher proportion of premarital conceptions in the 1880 and 1890 cohorts: 22.8 per cent of women in the 1880 cohort and 22.1 per cent in the 1890 cohort conceived 
their first child prior to their marriage compared with 14.8 per cent of women in the $1860 / 70$ cohorts. The increase in the proportion of couples with premarital conceptions may be related to the increase in the age at marriage - in particular, the fall in the proportion of women who were teenagers when they married. As Carmichael (1996) has noted, when the age at marriage increases, the period of exposure to the risk of premarital pregnancy increases and thus the likelihood of couples marrying to legitimise their first child.

Table 7.5 Interval between marriage and first birth, complete group: 1860/70, 1880 and 1890 marriage cohorts, Tasmania

\begin{tabular}{|l|r|r|r|}
\hline Marriage cohort & $1860 / 70$ & 1880 & \multicolumn{1}{|c|}{1890} \\
\hline Age at marriage & \multicolumn{3}{|c|}{ Percentage } \\
\hline Premarital conception & 14.8 & 22.8 & 22.1 \\
\hline 8 to $<12$ months & 43.2 & 42.2 & 38.4 \\
\hline 12 to $<24$ months & 28.6 & 26.6 & 29.3 \\
\hline 24 to $<36$ months & 6.5 & 4.6 & 5.3 \\
\hline $36+$ months & 6.9 & 3.8 & 4.9 \\
\hline Total (\%) & 100.0 & 100.0 & 100.0 \\
\hline Total (no.) & 539 & 417 & 529 \\
\hline Mean/median & \multicolumn{3}{|c|}{ Months } \\
\hline Mean & 17.0 & 12.9 & 15.0 \\
\hline Median & 11.2 & 10.3 & 10.9 \\
\hline
\end{tabular}

As outlined in Chapter 1, those who argue that couples controlled their fertility by deliberate spacing behaviour consider these couples spaced their births from the earliest birth intervals. In the Tasmanian marriage cohorts, first interbirth intervals were much longer on average than the interval between marriage and the first birth but increased only slightly between the $1860 / 70$ and 1890 cohorts, from a mean of 23 months (median 21.4) to a mean of 24.4 months (median 22) (Table 7.6). The proportion of couples with a first interbirth interval of 36 months or more also increased slightly, from 7.1 per cent to 10.7 per cent. 
Table 7.6 First interbirth interval, complete group: 1860/70, 1880 and 1890 marriage cohorts, Tasmania

\begin{tabular}{|l|r|r|r|}
\hline Marriage cohort & $1860 / 70$ & \multicolumn{3}{|c|}{1880} & \multicolumn{1}{|c|}{1890} \\
\hline Age at marriage & \multicolumn{3}{|c|}{ Percentage } \\
\hline$<18$ months & 29.0 & 32.5 & 29.2 \\
\hline 18 to $<24$ months & 34.1 & 35.1 & 33.0 \\
\hline 24 to $<30$ months & 21.9 & 16.5 & 21.4 \\
\hline 30 to $<36$ months & 7.9 & 7.2 & 5.8 \\
\hline $36+$ months & 7.1 & 8.8 & 10.7 \\
\hline Total (\%) & 100.0 & 100.0 & 100.0 \\
\hline Total (no.) & 493 & 388 & 449 \\
\hline Mean/median & \multicolumn{3}{|c|}{ Months } \\
\hline Mean & 23.0 & 23.3 & 24.4 \\
\hline Median & 21.4 & 20.9 & 22.0 \\
\hline
\end{tabular}

Note: Excludes couples for whom the second birth is the last.

There was little change in the length of the second interbirth interval from the $1860 / 70$ to the 1890 cohorts, with the mean birth interval remaining about 26 months (median 23.4-23.7 months) (Table 7.7). As with the first interbirth interval, the proportion of couples with a second interbirth interval of 36 months or more increased slightly, from 11 per cent to 14.4 per cent.

Table 7.7 Second interbirth interval, complete group: 1860/70, 1880 and 1890 marriage cohorts, Tasmania

\begin{tabular}{|l|r|r|r|}
\hline Marriage cohort & $1860 / 70$ & \multicolumn{3}{|c|}{1880} & \multicolumn{1}{|c|}{1890} \\
\hline Age at marriage & 15.2 & 21.3 & 21.9 \\
\hline$<18$ months & 36.6 & 34.0 & 29.5 \\
\hline 18 to $<24$ months & 28.1 & 23.0 & 25.1 \\
\hline 24 to $<30$ months & 9.1 & 11.8 & 9.1 \\
\hline 30 to $<36$ months & 11.0 & 9.8 & 14.4 \\
\hline $36+$ months & 100.0 & 100.0 & 100.0 \\
\hline Total (\%) & 462 & 356 & 383 \\
\hline Total (no.) & \multicolumn{3}{|c|}{ Months } \\
\hline Mean/median & 26.0 & 25.4 & 26.1 \\
\hline Mean & 23.7 & 23.4 & 23.6 \\
\hline Median & \multicolumn{3}{|c}{} \\
\hline
\end{tabular}

Note: Excludes couples for whom the third birth is the last. 


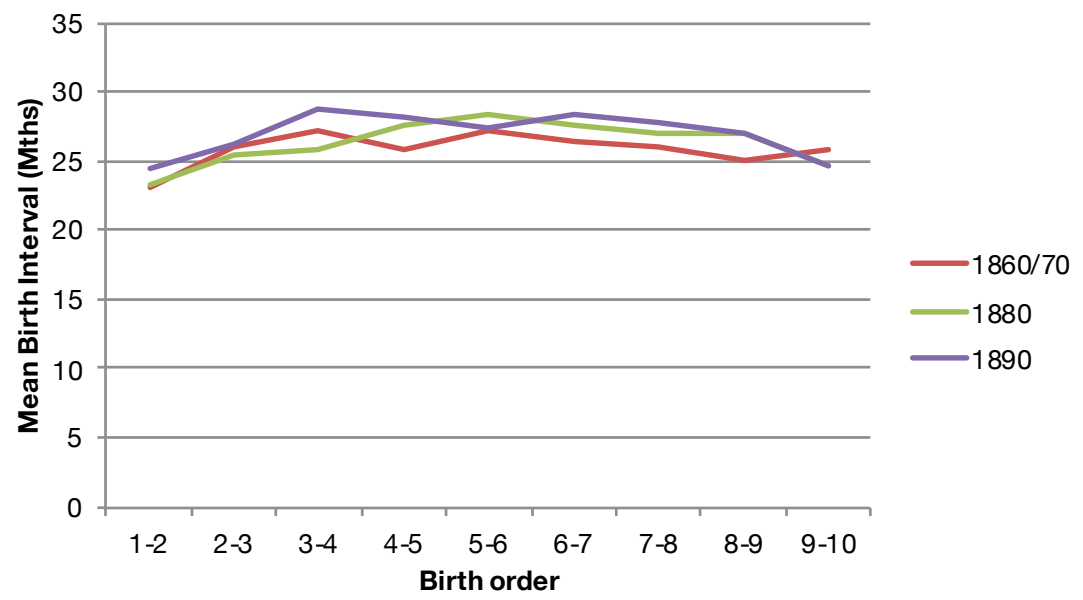

Figure 7.1 Mean birth intervals by birth order (excluding last), complete group: 1860/70, 1880 and 1890 marriage cohorts, Tasmania Source: Appendix A: Table A.21 (this volume).

For all interbirth intervals up to parity 10 , mean birth intervals were generally longest for the 1890 cohort, but they were longer for the $1860 / 70$ cohorts than the 1880 cohort at lower parities and shorter at higher parities (Figure 7.1). These differences were not large, mainly in the order of one to two months. In the 1860/70 cohorts, mean birth intervals were about two years at every parity, indicating the effect of breastfeeding practices on amenorrhoea (Tsuya et al. 2010). While there are no data on the extent of breastfeeding in the Australian colonies, a review of infant feeding in 19th-century Australia indicates that experts advocated breastfeeding for between nine and 18 months and concludes that 'mothers expected to breastfeed their infants, and most probably did so' (Hitchcock 1990: 21).

Last birth intervals were considerably longer than other birth intervals and increased across the cohorts, from a mean of 38.4 months (median 32.1) for the $1860 / 70$ cohorts to a mean of 46.2 months (median 36) for the 1890 cohort (Table 7.8). This was due to the increase in very long last birth intervals, with the proportion of last birth intervals that were 72 months or longer increasing from 7 per cent in the $1860 / 70$ cohorts to 16.5 per cent in the 1890 cohort. 
Table 7.8 Last interbirth intervals, complete group: 1860/70, 1880 and 1890 marriage cohorts, Tasmania

\begin{tabular}{|l|r|r|r|}
\hline Marriage cohort & $1860 / 70$ & 1880 & \multicolumn{1}{|c|}{1890} \\
\hline Birth interval & \multicolumn{3}{|c|}{ Percentage } \\
\hline$<18$ months & 8.2 & 7.6 & 6.8 \\
\hline 18 to $<24$ months & 15.6 & 14.2 & 13.7 \\
\hline 24 to $<30$ months & 20.6 & 16.4 & 17.3 \\
\hline 30 to $<36$ months & 13.2 & 14.2 & 11.7 \\
\hline 36 months to $<72$ months & 35.4 & 36.0 & 34.1 \\
\hline $72+$ months & 7.0 & 11.5 & 16.5 \\
\hline Total (\%) & 100.0 & 100.0 & 100.0 \\
\hline Total (no.) & 514 & 408 & 504 \\
\hline Mean/median & \multicolumn{3}{|c|}{ Months } \\
\hline Mean & 38.4 & 42.3 & 46.2 \\
\hline Median & 32.1 & 34.5 & 36.0 \\
\hline
\end{tabular}

Note: Includes couples with two or more births.

Some authors argue that examining birth intervals by final parity provides a better indication of whether families are practising stopping or spacing behaviour. It is generally agreed that in populations of natural fertility and those that control their fertility, the length of mean birth intervals is inversely related to final parity, with families with large numbers of children having the shortest mean birth intervals (Anderton and Bean 1985; Knodel 1987). With the practice of stopping, birth intervals may reduce for couples with moderate numbers of children, because they behave like those who have large families under conditions of natural fertility (shorter birth intervals) but decide to stop at much lower parities.

During the fertility transition in late 19th-century Utah, mean birth intervals by completed family size remained relatively unchanged (Anderton and Bean 1985). Anderton and Bean (1985) argue this is because families were practising both stopping and spacing behaviours to control their fertility. They claim that under conditions of natural fertility, having a small completed family size (with relatively long birth intervals) was due not to problems with fecundity, but reflected the fact that a small proportion of couples were deliberately both stopping and spacing their births. They consider the fall in fertility over the 19th century reflects an increasing proportion of couples both spacing and stopping their births to achieve these same birth patterns. 
Okun (1995) used her simulation model to investigate whether an analysis of birth intervals stratified by birth order and final parity could distinguish between stopping and spacing behaviours. In her model, she examined the last birth interval separately from the preceding intervals, because of the effects of failed stopping in increasing this interval. Okun's simulation showed that mean birth intervals prior to the last decreased with stopping behaviour and increased with spacing behaviour. She concludes that examining changes in mean birth intervals stratified by final parity, excluding the last, is a good method for identifying whether couples are stopping or spacing their births. However, she argues it is not possible to distinguish stopping from spacing behaviour by examining changes in the last birth interval, since the last birth interval increases with both stopping and spacing behaviours. It is worth noting that Okun's analysis involves modelling stopping or spacing behaviour, but not a combination of both, as argued by Anderton and Bean (1985).

Hionidou (1998) termed the interval between the first birth and the penultimate birth the 'overall' interval. In the Tasmanian marriage cohorts, the mean overall birth interval was inversely related to parity in every marriage cohort-for example, decreasing from 30.4 months for couples with three to four children to 22.9 months for couples with 11-16 children in the 1880 cohort (Table 7.9). There was, however, no consistent pattern in the change in the mean overall birth interval from the $1860 / 70$ to the 1890 cohorts for families of different parities. The mean overall birth interval decreased for couples with three or four children, from 33.7 to 29.6 months; it fell only slightly for couples with seven or more children and increased slightly for couples with five or six children. Overall, changes in the mean overall birth intervals were small, providing little evidence of increased spacing.

Table 7.9 Mean overall birth interval by number of children, complete group: 1860/70, 1880 and 1890 marriage cohorts, Tasmania

\begin{tabular}{|l|r|r|r|}
\hline Marriage cohort & \multicolumn{1}{|c|}{$1860 / 70$} & \multicolumn{1}{|c|}{1880} & \multicolumn{1}{c|}{1890} \\
\hline Number of children & \multicolumn{3}{|c|}{ Mean overall birth interval (months) } \\
\hline $3-4$ & 33.7 & 30.4 & 29.6 \\
\hline $5-6$ & 27.6 & 28.2 & 29.2 \\
\hline $7-8$ & 26.8 & 26.5 & 25.8 \\
\hline $9-10$ & 25.1 & 24.1 & 24.5 \\
\hline $11-16^{1}$ & 23.7 & 22.9 & 22.3 \\
\hline
\end{tabular}

${ }^{1}$ Mean in 1890 is illustrative only because of small numbers. 
Some scholars have put forward the view that age at marriage may affect birth spacing (Bumpass et al. 1978), since it is generally agreed that birth intervals are shorter when women marry very young (Finnas and Hoem 1980). Anderton and Bean (1985), however, were surprised to find that birth intervals were shorter in the Utah population for those marrying after age 25 years compared with those marrying between the ages of 21 and 25 years. They argue that women who marry at older ages have shorter birth intervals because they aim to have a specific number of children but have less time in which to achieve this than those who marry younger.

Some demographers who consider that both spacing and stopping played a role in the fertility transition argue that there are other questions about the fertility decline that need to be addressed-for instance, what proportion of couples in a marriage cohort were effective in controlling their fertility and how many children did they have on average (David and Sanderson 1988; David et al. 1988)? They developed a method called Cohort Parity Analysis (CPA) to enable such questions to be answered in historical populations that practise both stopping and spacing. CPA derives lower and upper bound estimates for the proportion of a population adopting fertility control by comparing the parity progression ratios of women in the population of interest (the 'target' population) by age at marriage and duration of marriage, with the parity progression ratios of women in a population that is similar, but where there is no fertility control (the 'model' population) (David and Sanderson 1988). The average final parity of women controlling their fertility can also be calculated within the CPA framework. Women in both the target and the model populations are in their first marriage.

Okun (1994) evaluated this method using her simulation model and concluded that CPA is not a useful method of identifying fertility control practices in the early stages of a fertility transition. This was mainly because of her concerns about the large biases in CPA bounds introduced by even small differences between the target and the model populations in relation to 'length of the post-partum non-susceptible period, fecundability and pre-marital exposure to pregnancy' (Okun 1994: 222). 


\section{Failed stopping}

There is clearly considerable disagreement among demographers about the extent to which long last birth intervals are due to failed stopping, spacing or decreasing fecundity. An analysis of long last birth intervals in the Tasmanian marriage cohorts— that is, intervals of six years or moremay inform this debate. While six years is taken as the minimum length of a long birth interval, some last birth intervals were considerably longer. In the 1890 cohort, for instance, 18 per cent of long last birth intervals were 10 years or more.

Where last birth intervals were long, there was variation between the marriage cohorts in the parity of the last birth (Table 7.10). In the 1860/70 cohorts, long last birth intervals were spread fairly evenly among the parities, with the highest proportion of intervals, 16.7 per cent, between parities seven and eight. Long last birth intervals were more concentrated at specific parities in the other two cohorts. In the 1880 cohort, 21.3 per cent of long last birth intervals were between parities four and five, while in the 1890 cohort, 27.7 per cent were between parities three and four and 19.3 per cent were between four and five. This shows a substantial proportion of couples in the 1880 cohort were trying to stop after parity four and those in the 1890 cohort after parities three and four.

Table 7.10 Parity of last birth, where last birth interval is six years or more, complete group: 1860/70, 1880 and 1890 marriage cohorts, Tasmania

\begin{tabular}{|c|c|c|c|}
\hline Marriage cohort & $1860 / 70$ & 1880 & 1890 \\
\hline Parity & \multicolumn{3}{|c|}{ Percentage } \\
\hline Two & 8.3 & 6.4 & 10.8 \\
\hline Three & 2.8 & 10.6 & 8.4 \\
\hline Four & 8.3 & 10.6 & 27.7 \\
\hline Five & 8.3 & 21.3 & 19.3 \\
\hline Six & 8.3 & 14.9 & 9.6 \\
\hline Seven & 13.9 & 8.5 & 8.4 \\
\hline Eight & 16.7 & 10.6 & 4.8 \\
\hline Nine & 8.3 & 8.5 & 3.6 \\
\hline Ten & 13.9 & 6.4 & 2.4 \\
\hline Eleven & 8.3 & 2.1 & 4.8 \\
\hline Twelve & 2.8 & 0.0 & 0.0 \\
\hline Total (\%) & 100.0 & 100.0 & 100.0 \\
\hline Total (no.) & 36 & 47 & 83 \\
\hline
\end{tabular}

Note: Includes couples with two or more births. 
It is interesting to examine the length of the interval preceding the long last birth interval, since if long last birth intervals are due to spacing behaviour, the penultimate birth interval should also be relatively long. Most couples with a long last birth interval, however, had a relatively short penultimate birth interval (Table 7.11). More than half of couples in the 1880 cohort and three-quarters of couples in the 1860/70 and 1890 cohorts had penultimate birth intervals of less than three years. It seems highly unlikely this pattern of birth intervals represents spacing behaviour.

Table 7.11 Length of the penultimate interval, where last birth interval is six years or more, complete group: 1860/70, 1880 and 1890 marriage cohorts, Tasmania

\begin{tabular}{|l|r|r|r|}
\hline Marriage cohort & $1860 / 70$ & \multicolumn{3}{|c|}{1880} & \multicolumn{1}{|c|}{1890} \\
\hline Birth interval & 36.4 & 36.4 & 37.8 \\
\hline$<24$ months & 39.4 & 22.7 & 39.2 \\
\hline 24 to $<36$ months & 15.2 & 29.5 & 12.2 \\
\hline 36 to $<54$ months & 3.0 & 9.1 & 9.5 \\
\hline 54 to $<72$ months & 6.1 & 2.3 & 1.4 \\
\hline $72+$ months & 100.0 & 100.0 & 100.0 \\
\hline Total (\%) & 33 & 44 & 74 \\
\hline Total (no.) & & & \\
\hline
\end{tabular}

Note: Includes couples with three or more births.

As noted above, last birth intervals tend to be longer than other birth intervals because of the decline in fecundity that women experience as they age. It has been shown, however, that in populations where families practise little or no fertility control, women's fecundity does not decline to any great extent until after age 35 years, and only declines sharply after age 39 years (Menken et al. 1986). Half of the women in the 1890 cohort with long last birth intervals and 42 per cent in the 1880 cohort were under 30 years of age at the penultimate birth (Table 7.12). It seems very unlikely these long birth intervals were due to declining fecundity and more likely they were due to failed stopping. Given that 'fertility, compared with that of women [aged] 20 to 24 , is reduced on average by ... 14 per cent for those aged 30 to 34 ' (Menken et al. 1986: 1389), it is also unlikely that women who were aged 30 to 34 at their penultimate birth had such long birth intervals due to reduced fecundity. 
Table 7.12 Age of mother at the penultimate birth, where last birth interval is six years or more, complete group: $1860 / 70,1880$ and 1890 marriage cohorts, Tasmania

\begin{tabular}{|l|r|r|r|}
\hline Marriage cohort & $1860 / 70$ & 1880 & \multicolumn{1}{|c|}{1890} \\
\hline Age of mother & \multicolumn{3}{|c|}{ Percentage } \\
\hline$<25$ years & 8.3 & 2.1 & 14.5 \\
\hline 25-29 years & 8.3 & 40.4 & 34.9 \\
\hline 30-34 years & 41.7 & 27.7 & 30.1 \\
\hline 35-39 years & 41.7 & 29.8 & 18.1 \\
\hline 40+ years & 0.0 & 0.0 & 1.2 \\
\hline Missing & 0.0 & 0.0 & 1.2 \\
\hline Total (\%) & 100.0 & 100.0 & 100.0 \\
\hline Total (no.) & 36 & 47 & 83 \\
\hline
\end{tabular}

Note: Includes couples with two or more births.

As noted above, long last birth intervals have also been attributed to couples having stopped childbearing but changing their minds because one of their children died (Knodel 1987). Only a small proportion of families with long last birth intervals had a child die during the interval: seven in the $1860 / 70$ cohorts, four in the 1880 cohort and 12 in the 1890 cohort. For 16 of these couples, the interval between the death of a child and the birth of the last child was six years or longer. Of the seven families where the time between the child's death and the last birth was shorter than six years, only three couples had a gap of less than four years (Table 7.13). This indicates that most of the couples who experienced a child's death during the long last birth interval did not have their last birth in response to this death.

Table 7.13 Families with long last birth intervals where the gap between death of a child and last birth was less than six years (seven families), complete group: 1860/70, 1880 and 1890 marriage cohorts, Tasmania

\begin{tabular}{|l|r|r|r|r|r|r|r|}
\hline Marriage cohort & $1860 / 70$ & $1860 / 70$ & $1860 / 70$ & 1880 & 1880 & 1890 & 1890 \\
\hline Last birth interval (months) & 73.4 & 115.7 & 87.1 & 73.7 & 80.4 & 120.2 & 115.7 \\
\hline $\begin{array}{l}\text { Time between death and } \\
\text { last birth interval (months) }\end{array}$ & 53.0 & 36.0 & 38.6 & 10.9 & 67.3 & 50.0 & 49.0 \\
\hline Age at death (years) & 1.7 & 10.9 & 6.9 & 5.3 & 2.6 & 5.8 & 11.6 \\
\hline
\end{tabular}




\section{Stopping, starting and spacing: McDonald's formula}

McDonald (1984) developed a decomposition technique to identify the extent to which changes in final parity can be attributed to stopping, starting or spacing behaviours. A modified version of McDonald's formula was used by Knodel (1987) in his analysis of the marital fertility of German village populations in the 18th and 19th centuries. The McDonald method has been used in many analyses of the fertility decline in countries of Western Europe (for example, Van Bavel and Kok 2005; Derosas 2006; Reher and Sanz-Gimeno 2007; van Poppel et al. 2012).

As modified by Knodel, the formula is $C E B=1+(L-F) / I$, where $C E B$ is the mean number of children ever born, $F$ is the mean age at first birth, $L$ is the mean age at last birth and $I$ is the mean birth interval. Using decomposition analysis, the contribution of mean age at first birth, mean age at last birth and interbirth intervals to changes in the number of children ever born can be assessed by substituting the relevant indicator into the equation for the base year and estimating its impact on the number of children ever born. Although McDonald (1984) originally advocated using a stepwise standardisation approach, Knodel (1987) presented the changes attributable to each factor separately. Because the different factors interact with one another, the sum of the changes attributed to each component $(F, L, I)$ does not necessarily add to the difference in the number of children ever born (CEB) (Knodel 1987). The difference between the two, however, is generally small and the interaction effects can be ignored.

The components used in the formula are presented in Table 7.14. Note that the data for the 1880 and 1890 cohorts on mean numbers of children ever born and mean birth interval are slightly different from those presented elsewhere, because these data exclude couples for whom the mother's age is missing. 
Table 7.14 Mean children ever born, mean age of mother at first birth, mean age of mother at last birth and mean birth interval, complete group: 1860/70, 1880 and 1890 marriage cohorts, Tasmania

\begin{tabular}{|l|r|r|r|}
\hline Marriage cohort & $1860 / 70$ & 1880 & \multicolumn{3}{|c|}{1890} \\
\hline Component of change & 7.91 & 7.07 & 5.64 \\
\hline Mean children ever born & 23.20 & 23.10 & 24.30 \\
\hline Mean age of mother at first birth (years) & 38.80 & 37.50 & 36.10 \\
\hline Mean age of mother at last birth (years) & 2.27 & 2.37 & 2.54 \\
\hline Mean birth interval (years) & 539 & 414 & 524 \\
\hline Total (no.) & & &
\end{tabular}

Note: Excludes couples for whom mother's age is missing.

Using the McDonald formula, comparing the $1860 / 70$ and 1880 cohorts, the drop in the mean number of children ever born $(-0.84)$ was due mainly to the fall in the mean age at last birth $(-0.59)$ and an increase in the length of the mean birth interval $(-0.3)$ (Table 7.15). The very small decrease in the mean age at first birth had a negligible effect $(+0.01)$. Comparing the $1860 / 70$ and 1890 cohorts, the fall in the mean number of children ever born $(-2.27)$ was primarily due to the fall in the mean age at last birth (-1.22), while the increase in the length of the mean birth interval and in the mean age of the mother at the first birth also made substantial contributions $(-0.74$ and -0.51 , respectively).

Table $7.15 \mathrm{Impact}$ of age at first birth, age at last birth and birth intervals for children ever born, McDonald method, complete group: 1860/70, 1880 and 1890 marriage cohorts, Tasmania

\begin{tabular}{|l|r|r|}
\hline Marriage cohort & $\begin{array}{c}1860 / 70 \text { compared } \\
\text { with } 1880\end{array}$ & $\begin{array}{r}1860 / 70 \text { compared } \\
\text { with } 1890\end{array}$ \\
\hline Component of change & +0.01 & -0.51 \\
\hline Mean age of mother at first birth & -0.59 & -1.22 \\
\hline Mean age of mother at last birth & -0.30 & -0.74 \\
\hline Mean birth interval & -0.84 & -2.27 \\
\hline Children ever born &
\end{tabular}

Note: Excludes couples for whom mother's age is missing. 
Both Knodel and McDonald (Knodel 1987; McDonald and Knodel 1989: 472) agree that the formula cannot 'capture all of the subtleties and complexities involved in changes in stopping and spacing behaviour'. For instance, they acknowledge that a fall in the mean age at last birth $(L)$, which the formula attributes to stopping, can in some part be attributed to spacing, but argue that the effect is very small. Knodel (1987) also acknowledges that while increases in the mean birth interval $(I)$ are attributed to spacing, this measure includes the last birth interval, changes in which may be due to 'failed' stopping. Both authors argue that, despite these limitations, the formula can be used with confidence to distinguish the broad effects of the different practices. When McDonald originally developed the formula, he advocated its use as a tool for 'first-stage analysis' and saw it as being followed by a 'second-stage analysis', in which findings would be examined at the individual level (McDonald 1984: 27).

Okun (1995) used her simulation model to look at the accuracy of McDonald's formula in distinguishing between stopping and spacing practices. She concluded that, since the effects of stopping behaviour are primarily shown through changes in the mean age at last birth and spacing behaviour through increases in the mean birth intervals, the McDonald formula 'provides a convenient device for roughly apportioning changes in CEB into its components' (Okun 1995: 92).

Van Bavel (2004b), however, argues that McDonald's technique can differentiate between stopping and spacing only when the population practising fertility control adopts either stopping or spacing behaviour, but not both. He claims that when one section of the population is practising stopping and another practising spacing behaviour, the McDonald method will disguise the effects of stopping behaviour on both the mean age at last birth and the mean birth intervals.

\section{Multivariate analysis}

Bivariate analysis, while an important first step in any analysis of the fertility transition, is limited in its explanatory power. In the past 20 or so years, multivariate methods have become commonly used by historical demographers to examine the fertility decline (Gutmann and Alter 1993; Van Bavel 2004b). Van Bavel (2004b) proposes two multivariate analysis methods for investigating stopping and spacing behaviours: logistic regression and event history analysis (or survival analysis). Survival analysis 
is useful in analysing datasets for which we do not have complete birth histories (Gutmann and Alter 1993). However, survival analysis does not allow us to distinguish spacing from stopping behaviour, since it models the risk of having the next birth, which can reflect either the length of the next birth interval or whether the woman stops having children (Berger et al. 2009; Gray et al. 2010). Since my dataset includes only couples who have completed their childbearing, I use logistic regression to examine stopping behaviour and survival analysis on closed birth intervals to examine spacing behaviour. I was unable to fit a logistic regression model to examine parity progression, so I used survival analysis to examine the risks of a woman at a specific parity proceeding to the next parity.

\section{Stopping behaviour}

\section{Logistic regression}

In this section, I investigate stopping behaviour using logistic regression to examine the determinants of any given birth being the last (Van Bavel 2004b; Berger et al. 2009). All families with one or more children are included in the analysis.

The dependent variable is whether a birth is the last birth (with ' 1 ' = last birth and ' 0 ' = not last birth).

Many of the following covariates included in the logistic regression model have been examined in the bivariate analysis in Chapter 6. The covariates used in the model relate to the theories of fertility decline discussed in Chapter 1 or are associated with a woman's fecundity:

- Age of wife at marriage.

- Difference in age between husband and wife.

- Husband's socioeconomic status.

- Type of geographic location.

- Religion.

- Literacy status of husband and wife.

- Whether a pregnancy resulted in the birth of twins.

- Whether the child died in infancy when the wife was not pregnant with another child.

- The number of children alive at the beginning of the birth intervalthat is, the number of children born to the couple less the number of children who died under the age of 15 years. 
- The number of children who had died (under the age of 15 years) at the beginning of the birth interval.

- The sex composition of the surviving children at the beginning of the birth interval.

In this analysis of Tasmanian marriage cohorts, the sex composition of the family is divided into three categories: more surviving girls than boys, more surviving boys than girls and equal numbers of surviving boys and girls. I chose this categorisation, rather than a categorisation based on whether there were any boys or any girls in the family, because of the very small number of families in the Tasmanian marriage cohorts above parity four who had surviving children of one sex only.

Testing for multicollinearity of the covariates (using 'collin' in STATA) showed the covariates in the model are not highly correlated. Descriptive statistics of the covariates used in the logistic regression model are shown in Appendix A: Table A.22.

The model shows there are many covariates that are significantly associated with stopping behaviour (Table 7.16).

The mother's age at the birth of a child and her age at marriage were important determinants of whether a mother stopped childbearing. The older a mother was at the birth of a child, the more likely she was to stop childbearing. The odds of stopping for a mother who had a birth at age 30 years or older were 4.22 times the odds for women who had a birth aged under 20 years $(p=0.000)$. Similarly, the older a woman was at marriage, the more likely it was the birth would be her last. The odds of stopping childbearing for a woman who married at 25 years or older were 2.22 times $(\mathrm{p}=0.000)$ the odds for a woman who married under 20 years of age.

Controlling for all other factors, the marriage cohort was a significant determinant of stopping childbearing. The odds of stopping childbearing for a woman in the 1880 cohort were 1.42 times, and the odds for a woman in the 1890 cohort 2.22 times, the odds for a woman in the $1860 / 70$ cohorts $(\mathrm{p}=0.000)$. 
In relation to occupational status, farmers and unskilled workers were significantly less likely to stop childbearing than white-collar workers (odds $=0.63$ and 0.65 , respectively; $\mathrm{p}=0.000$ ) as were skilled workers (odds $=0.81, \mathrm{p}<0.05$ ). Couples living in rural areas were significantly less likely to stop childbearing than those in urban areas (odds $=0.69$, $\mathrm{p}=0.000)$. No significant differences were found between couples according to their religion or literacy status.

Having a twin birth was not a significant determinant of stopping. Having a child die as an infant while the mother was not pregnant with another was also not significant, but the more infant and/or child deaths the family had experienced at the birth of a child, the more likely they were to stop childbearing (odds $=1.28, p=0.000$ ). The number of surviving children affected the likelihood of stopping, with the odds of stopping increasing by 24 per cent for each additional surviving child $(\mathrm{p}=0.000)$. However, the sex composition of the surviving children was not significantly associated with stopping.

Table 7.16 Logistic regression of the probability that a birth is the last, complete group: 1860/70, 1880 and 1890 marriage cohorts, Tasmania

\begin{tabular}{|c|c|c|c|c|}
\hline \multirow{2}{*}{$\begin{array}{l}\text { Covariate } \\
\text { Intercept }\end{array}$} & \multirow{2}{*}{$\begin{array}{r}\begin{array}{l}\text { Odds } \\
\text { ratio }\end{array} \\
0.01 \\
\end{array}$} & \multirow{2}{*}{$\begin{array}{c}\begin{array}{c}\text { Standard } \\
\text { error }\end{array} \\
0.003\end{array}$} & \multicolumn{2}{|c|}{ Significance $(p)$} \\
\hline & & & 0.000 & ** \\
\hline \multicolumn{5}{|l|}{ Mother's age at birth } \\
\hline$<30$ years (ref.) & 1.00 & - & - & \\
\hline 30 to $<35$ years & 1.44 & 0.237 & 0.027 & * \\
\hline $35+$ years & 4.22 & 0.700 & 0.000 & ** \\
\hline \multicolumn{5}{|l|}{ Mother's age at marriage } \\
\hline$<20$ years (ref.) & 1.00 & - & - & \\
\hline 20 to $<25$ years & 1.51 & 0.120 & 0.000 & ** \\
\hline $25+$ years & 2.22 & 0.259 & 0.000 & ** \\
\hline \multicolumn{5}{|l|}{ Age difference between couple } \\
\hline $\begin{array}{l}\text { Same age or husband up to } 5 \text { years older } \\
\text { (ref.) }\end{array}$ & 1.00 & - & - & \\
\hline Wife older & 0.94 & 0.088 & 0.544 & \\
\hline Husband 5+ years older & 1.07 & 0.074 & 0.352 & \\
\hline \multicolumn{5}{|l|}{ Marriage cohort } \\
\hline $1860 / 70$ cohorts (ref.) & 1.00 & - & - & \\
\hline 1880 cohort & 1.42 & 0.111 & 0.000 & ** \\
\hline 1890 cohort & 2.20 & 0.172 & 0.000 & $\star \star$ \\
\hline
\end{tabular}




\begin{tabular}{|c|c|c|c|c|}
\hline Covariate & $\begin{array}{l}\text { Odds } \\
\text { ratio }\end{array}$ & $\begin{array}{l}\text { Standard } \\
\text { error }\end{array}$ & \multicolumn{2}{|c|}{ Significance $(p)$} \\
\hline \multicolumn{5}{|l|}{ Socioeconomic status } \\
\hline White-collar (ref.) & 1.00 & - & - & \\
\hline Skilled & 0.81 & 0.085 & 0.041 & * \\
\hline Farmers & 0.62 & 0.059 & 0.000 & ** \\
\hline Lower-skilled & 0.86 & 0.098 & 0.201 & \\
\hline Unskilled & 0.65 & 0.062 & 0.000 & ** \\
\hline \multicolumn{5}{|l|}{ Type of geographic location } \\
\hline Urban area in Tasmania (ref.) & 1.00 & - & - & \\
\hline Rural area in Tasmania & 0.69 & 0.053 & 0.000 & ** \\
\hline Another colony & 1.06 & 0.116 & 0.567 & \\
\hline \multicolumn{5}{|l|}{ Religion } \\
\hline Anglican (ref.) & 1.00 & - & - & \\
\hline Catholic & 0.85 & 0.089 & 0.119 & \\
\hline Presbyterian & 1.05 & 0.104 & 0.601 & \\
\hline Methodist & 0.88 & 0.077 & 0.157 & \\
\hline Other Nonconformist & 1.01 & 0.093 & 0.901 & \\
\hline \multicolumn{5}{|l|}{ Literacy status of husband and wife } \\
\hline Both literate (ref.) & 1.00 & - & - & \\
\hline Husband and/or wife illiterate & 0.96 & 0.092 & 0.667 & \\
\hline Twin birth & 1.60 & 0.407 & 0.063 & \\
\hline $\begin{array}{l}\text { Child dies as infant before conception } \\
\text { of another }\end{array}$ & 0.88 & 0.115 & 0.324 & \\
\hline Number of child deaths & 1.28 & 0.045 & 0.000 & ** \\
\hline Number of surviving children & 1.24 & 0.019 & 0.000 & ** \\
\hline \multicolumn{5}{|l|}{ Sex composition of surviving children } \\
\hline More surviving girls than boys (ref.) & 1.00 & - & - & \\
\hline More surviving boys than girls & 0.96 & 0.065 & 0.586 & \\
\hline Equal numbers of surviving boys and girls & 0.98 & 0.090 & 0.798 & \\
\hline \multicolumn{5}{|l|}{ No. of births $=9,923$} \\
\hline \multicolumn{5}{|c|}{ Hosmer-Lemeshow chi2(8) $=4.91$ Prob $>$ chi2 $=0.7673$} \\
\hline
\end{tabular}


Van Poppel et al. (2012) argue that actual family size is the most important variable for understanding the fertility decline, not the number of children born to the family. I was unable to include all three covariates-the number of children born to the family, the number of surviving children and the number of infant and child deaths - in my model because of multicollinearity. However, when I ran the model substituting the covariate 'number of children' for the covariate 'number of infant and child deaths', I found the number of surviving children was no longer significantly associated with stopping (odds ratio $=0.97, \mathrm{p}=0.452$ ), but the 'number of children' was a significant determinant of stopping (odds ratio $=1.28, \mathrm{p}=0.000$ ).

Szreter's (1996) analysis of fertility in 19th-century England and Wales shows that mining families had very high fertility. As noted, mining was a very important industry in late 19th-century Tasmania. In the logistic regression model presented above, 'miners' were classified as 'lowerskilled' workers. No significant differences were found between lowerskilled workers and white-collar workers in the likelihood of stopping childbearing (odds ratio $=0.86, \mathrm{p}=0.201$ ). I ran the same model for the 1890 marriage cohort only, classifying 'miners' separately and including the other lower-skilled workers in the skilled category. Using this classification, there were no significant differences between miners and white-collar workers in stopping childbearing or between skilled workers and white-collar workers. For miners, the odds ratio was $1.18(\mathrm{p}=0.554)$ and for skilled workers it was $0.83(\mathrm{p}=0.264)$.

In summary, the logistic regression shows that the older a woman was at the birth of her child, the more likely she was to stop childbearing. Similarly, the older a woman was at marriage, the more likely she was to stop childbearing. Women in the 1880 cohort were more likely to stop childbearing than those in the $1860 / 70$ cohorts, while women in the 1890 cohort were even more likely to stop. Farmers, unskilled workers and skilled workers were less likely to stop than white-collar workers, and people living in rural areas of Tasmania were less likely to stop than those living in urban areas. The age difference between husband and wife, religion, literacy and giving birth to twins had no significant association with stopping. However, the more surviving children the couple had, the more likely they were to stop, but the sex of these children had no significant association with stopping. Having an infant die while the mother was not pregnant had no significant association with stopping, but the more infant and child deaths the couple experienced, the more likely they were to stop. 
To ascertain whether these findings were affected by couples who had all their births outside the colony, I ran the same model only for couples who had at least one birth in Tasmania. The results were almost identical, except that for those with at least one birth in Tasmania, skilled workers were not significantly less likely to stop childbearing than white-collar workers (odds ratio $=0.83, \mathrm{p}=0.076$ ).

I also ran the model with interaction effects to see whether the relationships within the socioeconomic groups, religious groups and groups living in different geographic areas were consistent across cohorts. I found the interaction effects were not significant, so there was no evidence of any differences in the relationships within the groups in the different marriage cohorts.

\section{Predicted probability}

The predicted probability of a birth being the last (calculated from the logistic regression model) also showed the same patterns across cohorts. While the predicted probability of stopping increased over the marriage cohorts, it was highest for white-collar workers in every cohort and lowest for farmers and unskilled workers (Figure 7.2). The predicted probability of stopping for white-collar workers was 0.14 in the 1860/70 cohorts, compared with 0.10 for farmers. By the 1890 cohort, the predicted probability of stopping had increased to 0.24 for white-collar workers and 0.18 for farmers.

Women who married at age 20-24 years, gave birth at 30 years or older and had a husband who was the same age or one to four years older were the most common group in every cohort. The predicted probability of stopping was higher for this group of women than for all women (Figure 7.3). However, the pattern according to socioeconomic status was the same. For white-collar workers, the predicted probability of stopping was 0.19 in the $1860 / 70$ cohorts and rose to 0.32 in the 1890 cohort. The comparable probabilities for farmers were 0.13 and 0.24 , respectively. 


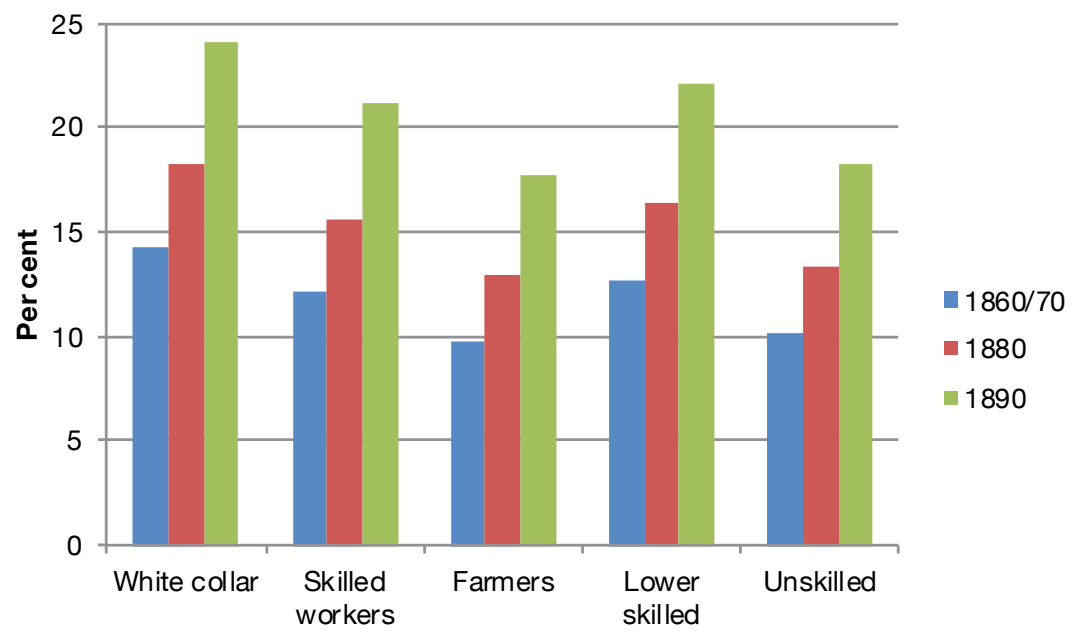

\section{Socioeconomic status}

Figure 7.2 Predicted probability that a birth is the last by socioeconomic status, complete group: 1860/70, 1880 and 1890 marriage cohorts, Tasmania

Source: Appendix A: Table A.21 (this volume).

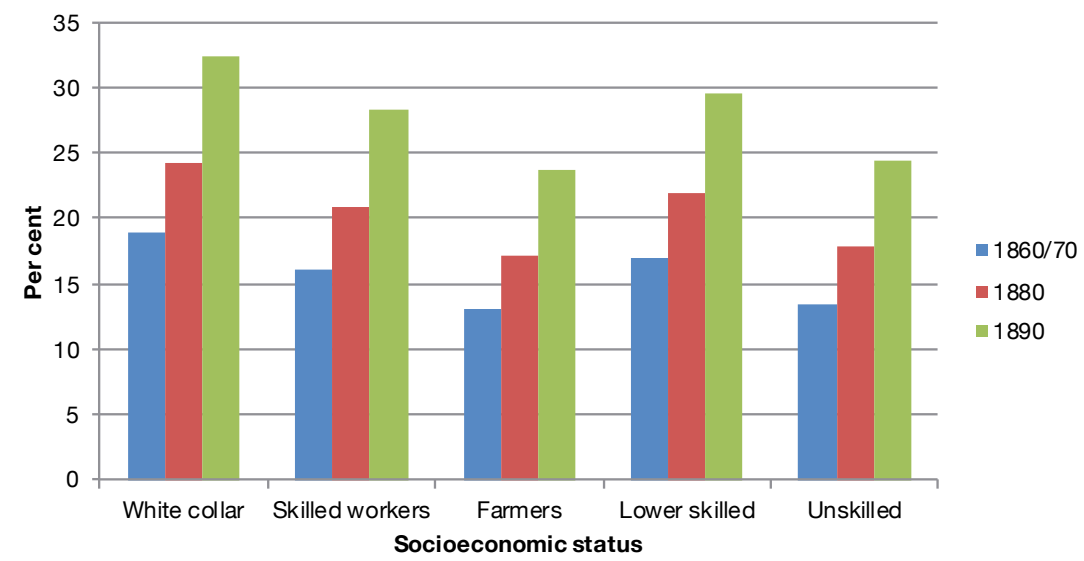

Figure 7.3 Predicted probability that a birth is the last by socioeconomic status for women married at age 20-24 years, giving birth at 30+ years and with a husband the same age or 1-4 years older, complete group: 1860/70, 1880 and 1890 marriage cohorts, Tasmania

Source: Appendix A: Table A.24 (this volume). 
The predicted probability that a birth was the last increased over the cohorts both for couples living in urban areas and for couples in rural areas and was higher for couples in urban areas in every marriage cohort (Figure 7.4). It increased from 0.13 to 0.23 across the marriage cohorts for those living in urban areas and from 0.10 to 0.18 for those living in rural areas.

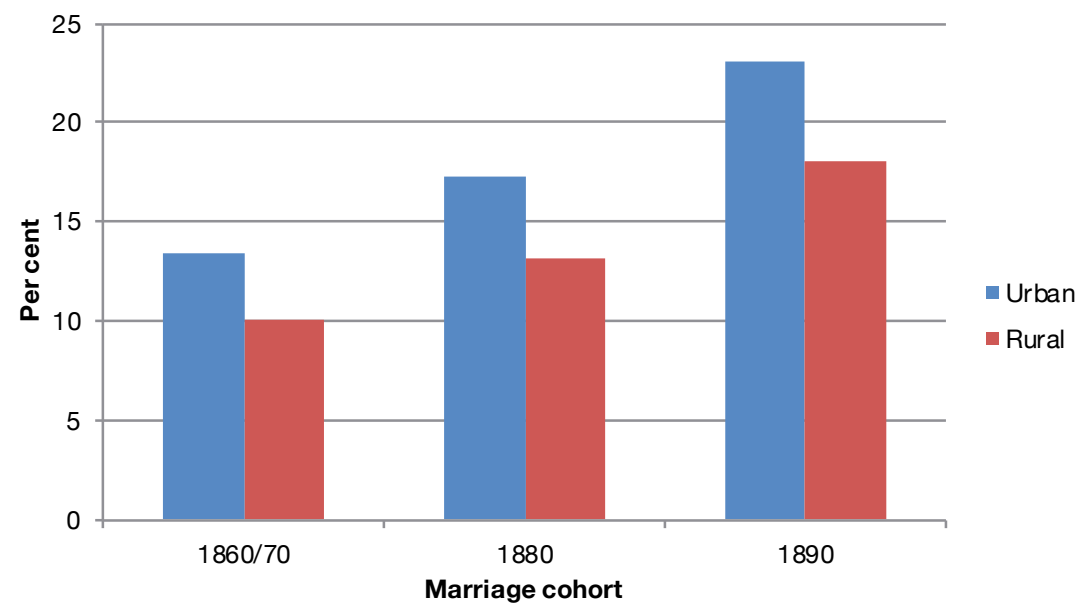

Figure 7.4 Predicted probability that a birth is the last by urban/rural location, complete group: 1860/70, 1880 and 1890 marriage cohorts, Tasmania

Source: Appendix A: Table A.25 (this volume).

As with socioeconomic status, although predicted probabilities of stopping were higher for women married at age 20-24 years, giving birth at 30 years or older with a husband the same age or one to four years older than for all women, the pattern by urban/rural location was the same (Appendix A: Table A.26). For women living in urban areas, the predicted probability of stopping having children increased from 0.18 to 0.31 from the $1860 / 70$ to the 1890 cohorts and for those living in rural areas from 0.13 to 0.24 , respectively. The predicted probability increased from 0.22 to 0.37 across the cohorts for this group of women who lived in urban areas and whose husband was a white-collar worker. 
The predicted probabilities of stopping with each surviving child can be used in the same way as parity progression ratios to calculate the proportion of women in each cohort predicted to have at least a specific number of surviving children (Figure 7.5). This shows that the predicted probability of women in each marriage cohort having a specific number of surviving children dropped steadily across the marriage cohorts. For instance, the predicted probability of women having four or more surviving children dropped from 0.84 in the $1860 / 70$ cohorts to 0.78 in the 1880 cohort and then to 0.69 in the 1890 cohort. Similarly, the predicted probability of women having 10 or more surviving children dropped from 0.34 in the $1860 / 70$ cohorts to 0.24 in the 1880 cohort and to 0.13 in the 1890 cohort. This indicates that couples in the 1880 and 1890 cohorts had different preferences regarding stopping childbearing.

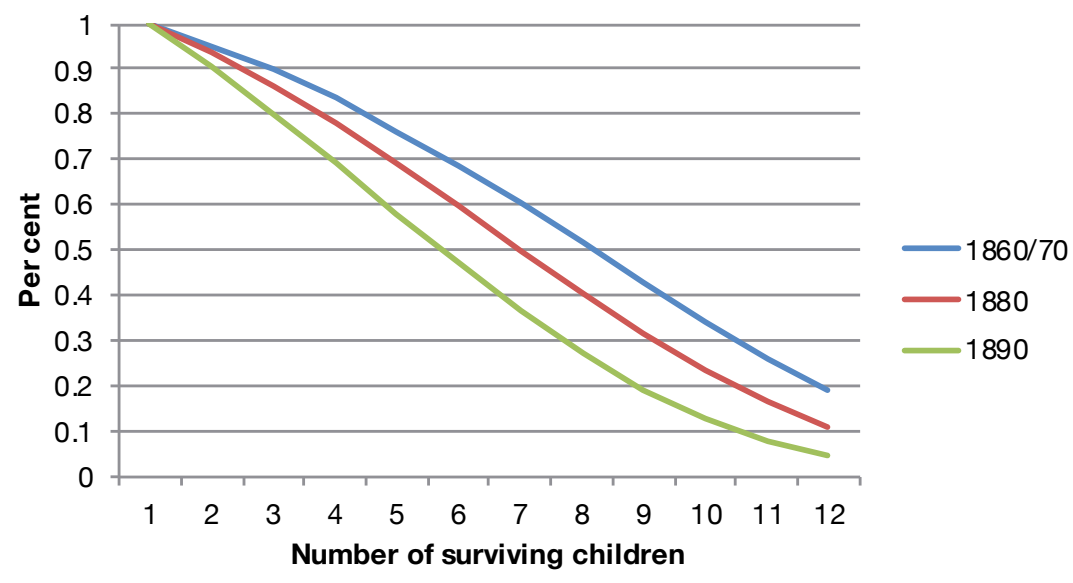

Figure 7.5 Predicted probability of women having at least a specific number of surviving children, complete group: 1860/70, 1880 and 1890 marriage cohorts, Tasmania

Source: Appendix A: Table A.27 (this volume).

\section{Birth spacing}

I originally intended to use the Cox regression to analyse the determinants of the length of birth intervals. However, when I undertook the 'ph test' and examined the survival curves, I found my data violated the proportional hazards assumption (Cleves et al. 2010: 208-9). I therefore used a piecewise exponential regression model for my analysis of birth spacing (Cleves et al. 2010: 329). 
I did not include the interval between marriage and the first birth in the model, since the marriage cohorts varied markedly in the proportion of first births that were conceived before marriage (see Table 7.2). Many other studies of spacing behaviour have concentrated on interbirth intervals for this reason (for example, Van Bavel and Kok 2004; Tsuya et al. 2010). Thus, the spacing analysis includes only couples with two or more children.

The dependent variable is the length of a birth interval in months (rounded to one decimal place).

I used the same covariates as in the logistic regression with the following exceptions:

- I used the crude parity at the beginning of the birth interval to control for fecundity, since women with higher parities tend to have shorter birth intervals (Van Bavel and Kok 2004, 2010).

- I excluded the number of deaths of infants and young children because of multicollinearity, as discussed above.

- I included a dummy variable that indicates whether the birth interval was the last, to account for the fact that last birth intervals are generally longer than other birth intervals even in circumstances where there is no fertility control (Van Bavel and Kok 2004).

Descriptive statistics of the covariates used in this model are shown in Appendix A: Table A.28.

The model shows there are many covariates that are significantly associated with the length of birth intervals (Table 7.17).

Birth spacing was associated with the mother's age at birth, with birth intervals significantly longer for women who gave birth when they were older. When women gave birth at age 30 years or older, for instance, their birth intervals were longer than when they gave birth under 25 years of age (relative risk $=0.65, \mathrm{p}=0.000$ ). In contrast, birth intervals were significantly shorter for women who married at older ages, with women marrying at 25 years or older having much shorter birth intervals than women who married under 20 years of age (relative risk $=1.55$, $\mathrm{p}=0.000$ ). The age difference between the husband and wife had no significant association with the length of the birth interval. 
Table 7.17 Estimated effects (relative risks) of various characteristics on the time to the next birth (closed birth intervals), complete group: 1860/70, 1880 and 1890 marriage cohorts, Tasmania

\begin{tabular}{|c|c|c|c|c|}
\hline \multirow{2}{*}{$\begin{array}{l}\text { Covariate } \\
\text { Constant }\end{array}$} & \multirow{2}{*}{$\begin{array}{c}\begin{array}{c}\text { Relative } \\
\text { risk }\end{array} \\
0.07\end{array}$} & \multirow{2}{*}{$\begin{array}{c}\text { Standard } \\
\text { error }\end{array}$} & \multicolumn{2}{|c|}{ Significance $(p)$} \\
\hline & & & 0.000 & ** \\
\hline \multicolumn{5}{|l|}{ Mother's age at birth of a child } \\
\hline$<25$ years (ref.) & 1.00 & - & - & \\
\hline $25-29$ years & 0.75 & 0.025 & 0.000 & ** \\
\hline $30+$ years & 0.65 & 0.029 & 0.000 & ** \\
\hline \multicolumn{5}{|l|}{ Mother's age at marriage } \\
\hline$<20$ years (ref.) & 1.00 & - & - & \\
\hline 20-24 years & 1.13 & 0.031 & 0.000 & ** \\
\hline $25+$ years & 1.55 & 0.073 & 0.000 & ** \\
\hline \multicolumn{5}{|l|}{ Age difference between couple } \\
\hline $\begin{array}{l}\text { Same age/husband up to } 5 \text { years } \\
\text { older (ref.) }\end{array}$ & 1.00 & - & - & \\
\hline Wife older & 1.05 & 0.037 & 0.214 & \\
\hline Husband $5+$ years older & 1.01 & 0.025 & 0.645 & \\
\hline \multicolumn{5}{|l|}{ Marriage cohort } \\
\hline 1860/70 cohorts (ref.) & 1.00 & - & - & \\
\hline 1880 cohort & 0.95 & 0.026 & 0.070 & \\
\hline 1890 cohort & 0.86 & 0.024 & 0.000 & $\star \star$ \\
\hline \multicolumn{5}{|l|}{ Socioeconomic status } \\
\hline White-collar (ref.) & 1.00 & - & - & \\
\hline Skilled & 1.00 & 0.040 & 0.859 & \\
\hline Farmers & 1.06 & 0.037 & 0.071 & \\
\hline Lower-skilled & 0.99 & 0.044 & 0.917 & \\
\hline Unskilled & 1.04 & 0.037 & 0.186 & \\
\hline \multicolumn{5}{|l|}{ Type of geographic location } \\
\hline Urban area in Tasmania (ref.) & 1.00 & - & - & \\
\hline Rural area in Tasmania & 1.07 & 0.030 & 0.014 & * \\
\hline Another colony & 1.05 & 0.046 & 0.309 & \\
\hline \multicolumn{5}{|l|}{ Religion } \\
\hline Anglican (ref.) & 1.00 & - & - & \\
\hline Catholic & 1.04 & 0.038 & 0.288 & \\
\hline Presbyterian & 1.00 & 0.036 & 0.992 & \\
\hline
\end{tabular}




\begin{tabular}{|c|c|c|c|c|}
\hline \multirow{2}{*}{$\begin{array}{l}\text { Covariate } \\
\text { Methodist }\end{array}$} & \multirow{2}{*}{$\begin{array}{c}\begin{array}{c}\text { Relative } \\
\text { risk }\end{array} \\
1.05 \\
\end{array}$} & \multirow{2}{*}{\begin{tabular}{|r|}
$\begin{array}{c}\text { Standard } \\
\text { error }\end{array}$ \\
0.032 \\
\end{tabular}} & \multicolumn{2}{|c|}{ Significance $(p)$} \\
\hline & & & 0.093 & \\
\hline Other Nonconformist & 0.93 & 0.031 & 0.036 & * \\
\hline \multicolumn{5}{|l|}{ Literacy status of husband and wife } \\
\hline Both literate (ref.) & 1.00 & - & - & \\
\hline Husband and/or wife illiterate & 0.96 & 0.031 & 0.224 & \\
\hline Twin birth & 1.05 & 0.127 & 0.669 & \\
\hline Number of children (crude parity) & 1.05 & 0.018 & 0.008 & ** \\
\hline Number of surviving children & 0.99 & 0.018 & 0.766 & \\
\hline $\begin{array}{l}\text { Child dies as infant before conception } \\
\text { of another }\end{array}$ & 1.45 & 0.067 & 0.000 & ** \\
\hline Ultimate birth interval & 0.42 & 0.014 & 0.000 & ** \\
\hline \multicolumn{5}{|l|}{ Sex composition of surviving children } \\
\hline More surviving girls than boys (ref.) & 1.00 & - & - & \\
\hline More surviving boys than girls & 1.01 & 0.024 & 0.640 & \\
\hline Equal numbers of surviving boys and girls & 0.96 & 0.030 & 0.237 & \\
\hline \multicolumn{5}{|l|}{ No. of birth intervals $=8,466$} \\
\hline
\end{tabular}

The marriage cohort was significantly associated with the length of the birth interval, with intervals significantly longer for women in the 1890 marriage cohort compared with the $1860 / 70$ cohorts (relative risk $=0.86$, $\mathrm{p}=0.000$ ). Women in rural areas of Tasmania had significantly shorter birth intervals than those in urban areas (relative risk $=1.07, \mathrm{p}<0.05$ ), while Other Nonconformists had significantly longer birth intervals than Anglicans (relative risk $=0.93, \mathrm{p}<0.05$ ). The socioeconomic status and literacy status of the husband and wife had no significant association with the length of the birth interval.

The higher the parity, the shorter was the birth interval (relative risk = $1.05, \mathrm{p}<0.01)$. Having a child die in infancy while the woman was not pregnant with another significantly reduced the time to the next birth (relative risk $=1.45, \mathrm{p}=0.000$ ). The last birth interval was significantly longer than the other birth intervals (relative risk $=0.42, \mathrm{p}<0.01$ ). 
However, the number of surviving children was not significantly related to the length of the birth interval, nor was their sex composition. Giving birth to twins also had no significant association with the length of the next birth interval.

To ascertain whether these findings were affected by couples who had all their births outside the colony, I ran the same model for couples who had at least one birth in Tasmania, with similar results, except the parity of the birth was only significant at the $\mathrm{p}<0.05$ level.

I ran the model with interaction effects to see whether there were differences in spacing within socioeconomic status, geographic location and religious groups across the cohorts. I found farmers (relative risk $=$ 1.26, $\mathrm{p}<0.05$ ) and unskilled workers (relative risk $=1.19, \mathrm{p}<0.05$ ) had significantly shorter birth intervals than white-collars workers in the 1890 cohort compared with the $1860 / 70$ cohorts (Appendix A: Table A.29). This indicates that white-collar workers were spacing their births in the 1890 cohort compared with other cohorts. Methodists (relative risk = $1.32, \mathrm{p}<0.05$ ) also had significantly shorter birth intervals than Anglicans in the 1880 cohort compared with the $1860 / 70$ cohorts. This finding is not explained by any differences in the composition of the Methodist group in the three cohorts, since the proportions of Wesleyan Methodists, Primitive Methodists and United Free Methodists in the 'Methodist' group did not change between the cohorts.

In summary, birth intervals were significantly longer for mothers who gave birth at older ages, but significantly shorter for mothers who married at older ages. Birth intervals were significantly longer for mothers in the 1890 cohort compared with the 1860/70 cohorts and significantly longer for Other Nonconformists compared with Anglicans. Rural women had significantly shorter birth intervals than urban women. The higher the parity of any birth, the shorter was the birth interval, while having an infant die while the woman was not pregnant with another led to significantly shorter birth intervals. The last birth interval was significantly longer than the other birth intervals.

The covariates of age difference between husband and wife, literacy of the husband and wife, number of surviving children, sex composition of those children and whether the preceding birth was a twin birth were not significantly associated with birth spacing. Socioeconomic status was not significantly associated with birth spacing in the overall model; 
however, when interaction effects were examined, in the 1890 cohort, farmers and unskilled workers had significantly shorter birth intervals than white-collar workers compared with the 1860/70 cohorts. In relation to religion, in the 1880 cohort, Methodists had significantly shorter birth intervals than Anglicans, compared with the 1860/70 cohorts.

\section{Parity progression}

To investigate the timing of the fertility decline, I used multivariate analysis to look at the determinants of parity progression. I wanted to see whether there were specific parities at which the 1880 and 1890 cohorts were likely to stop childbearing compared with the 1860/70 cohorts. As with the spacing analysis, I used a piecewise exponential regression model since my initial analysis showed the data violated the proportional hazards assumption. I did not estimate the effects of various characteristics on parity progression from parities 10 and over, because of the smaller numbers at these higher parities.

In interpreting the results, it is important to note that differences in the relative risk of having another birth can indicate differences either in spacing or in stopping behaviour.

I used the same covariates as in the logistic regression with some exceptions:

- I excluded the covariate 'number of children dead' at the parity since this was the obverse of the 'number of surviving children' at any parity.

- I excluded the covariate 'twin birth' because of the small number of twin births at each parity.

- I used a different categorisation for 'mother's age at the birth' at low and high parities because of the different numbers in the various categories as women aged. 'Mother's age at birth' was divided into three categories: $<25$ years, 25 to $<30$ years and $30+$ years for parities one to four; and $<30$ years, 30 to $<35$ years and $35+$ years for parities five and over.

The survival analysis models show that the covariates that consistently had significant effects on the risk of progressing from one parity to another were: mother's age at the birth of a child, mother's age at marriage, marriage cohort and whether the child died as an infant while the mother was not pregnant with another child (Tables 7.18a and 7.18b). Detailed information regarding each parity progression can be found in Moyle (2015: Tables A7.11-A7.19). 
At every parity except parity nine, the oldest mothers had a significantly lower risk of having another birth than the youngest mothers. For instance, among those with four children, mothers who were 30 years or older had a significantly lower risk of having another birth than those who were under 25 years of age (relative risk $=0.41, \mathrm{p}=0.000$ ).

Women's age at marriage, however, had the opposite effect, with mothers marrying at older ages having a significantly higher risk of having another birth at parities one, three, five and six. Among women with five children, for instance, women who married aged 20-24 years and those who married aged 25 years and over had a significantly higher risk of having another birth than those who married under 20 years of age (relative risks $=1.28$ and 2.60 , respectively; $\mathrm{p}<0.01$ ).

Women in the 1890 marriage cohort had a significantly lower risk of having another birth than women in the 1860/70 cohorts at all parities except parities one and nine, and even at parity one, the risk was almost significant (relative risk $=0.88, \mathrm{p}=0.051$ ). For those in the 1890 cohort, the relative risks of having another birth compared with those in the $1860 / 70$ cohorts ranged from 0.77 at parity two to 0.58 at parity four $(\mathrm{p}<0.01)$. Women in the 1880 cohort also had a significantly lower risk of having another birth compared with those in the 1860/70 marriage cohorts at parities four and five (relative risks $=0.72$ and 0.73 , respectively; $\mathrm{p}=0.000)$.

Women with a child dying as an infant while they were not pregnant had a significantly higher risk of having another birth than other mothers at all parities except four and eight, with the relative risks ranging from 1.4 at parity one to 1.65 at parity nine $(\mathrm{p}<0.01$, except at parity seven, where $\mathrm{p}<0.05)$.

Wives of farmers and unskilled workers had a significantly higher risk of having the next birth than white-collar workers at parities two and three $(\mathrm{p}<0.01)$. For farmers' wives, the relative risks were 1.31 at parity two and 1.43 at parity three, while for the wives of unskilled workers, they were 1.3 and 1.32, respectively. Farmers also had a significantly higher risk of having the next birth than white-collar workers at parities one and six $(\mathrm{p}<0.05)$. 
Women living in a rural area of Tasmania had a significantly higher risk of having another birth compared with women living in an urban area of Tasmania at parities two, four and seven, with a relative risk at parity four, for instance, of $1.23(\mathrm{p}<0.01)$.

Some of the other covariates were significantly associated with the risk of having another child at a few parities: the age difference between couples, religion, number of surviving children and sex composition of the surviving children.

Table 7.18a Estimated (significant) effects (relative risks) of various characteristics on parity progression from a piecewise exponential hazard model, complete group: 1860/70, 1880 and 1890 marriage cohorts, Tasmania

\begin{tabular}{|c|c|c|c|c|c|c|c|c|}
\hline \multirow{3}{*}{\begin{tabular}{|l|} 
\\
Mother's age at the birth \\
\end{tabular}} & \multicolumn{8}{|c|}{ Parity progression } \\
\hline & \multicolumn{2}{|c|}{$\begin{array}{c}1 \text { to } 2 \\
\text { Rel. risks }\end{array}$} & \multicolumn{2}{|c|}{$\begin{array}{l}2 \text { to } 3 \\
\text { Rel. risks }\end{array}$} & \multicolumn{2}{|c|}{$\begin{array}{l}3 \text { to } 4 \\
\text { Rel. risks }\end{array}$} & \multicolumn{2}{|c|}{$\begin{array}{c}\quad 4 \text { to } 5 \\
\text { Rel. risks }\end{array}$} \\
\hline & & & & & & & & \\
\hline$<25$ years (ref.) & 1.00 & & 1.00 & & 1.00 & & 1.00 & \\
\hline 25 to $<30$ years & 0.78 & * & 0.82 & * & 0.67 & ** & & \\
\hline $30+$ years & 0.41 & $\star *$ & 0.50 & ** & 0.37 & ** & 0.41 & ** \\
\hline \multicolumn{9}{|l|}{ Mother's age at marriage } \\
\hline$<20$ years (ref.) & 1.00 & & & & 1.00 & & & \\
\hline 20 to $<25$ years & & & & & 1.25 & * & & \\
\hline $25+$ years & 1.32 & * & & & 1.63 & ** & & \\
\hline \multicolumn{9}{|l|}{ Age difference between couple } \\
\hline $\begin{array}{l}\text { Same age/husband up to } 4 \text { years } \\
\text { older (ref.) }\end{array}$ & & & 1.00 & & & & & \\
\hline Wife older & & & 1.25 & ** & & & & \\
\hline Husband $5+$ years older & & & & & 0.87 & * & & \\
\hline \multicolumn{9}{|l|}{ Marriage cohort } \\
\hline $1860 / 70$ cohorts (ref.) & & & 1.00 & & 1.00 & & & \\
\hline 1880 cohort & & & & & & & 0.72 & ** \\
\hline 1890 cohort & & & 0.77 & ** & 0.67 & ** & 0.58 & ** \\
\hline \multicolumn{9}{|l|}{ Socioeconomic status } \\
\hline White-collar (ref.) & 1.00 & & 1.00 & & & & & \\
\hline Farmers & 1.24 & * & 1.31 & ** & 1.43 & ** & & \\
\hline Unskilled & & & 1.30 & ** & 1.32 & ** & & \\
\hline
\end{tabular}




\begin{tabular}{|c|c|c|c|c|c|c|c|c|}
\hline & \multicolumn{8}{|c|}{ Parity progression } \\
\hline & \multicolumn{2}{|c|}{$\begin{array}{c}1 \text { to } 2 \\
\text { Rel. risks }\end{array}$} & \multicolumn{2}{|c|}{$\begin{array}{l}2 \text { to } 3 \\
\text { Rel. risks } \\
\end{array}$} & \multicolumn{2}{|c|}{$\begin{array}{c}3 \text { to } 4 \\
\text { Rel. risks }\end{array}$} & \multicolumn{2}{|c|}{$\begin{array}{l}\quad 4 \text { to } 5 \\
\text { Rel. risks }\end{array}$} \\
\hline \multicolumn{9}{|l|}{ Type of geographic location } \\
\hline \multicolumn{9}{|l|}{ Urban area in Tasmania (ref.) } \\
\hline Rural area in Tasmania & & & 1.21 & ** & & & 1.23 & * \\
\hline $\begin{array}{l}\text { Child dies as infant before conception } \\
\text { of another }\end{array}$ & 1.40 & ** & 1.54 & ** & 1.62 & ** & & \\
\hline Sex composition of surviving children & n.a. & & & & & & & \\
\hline More surviving girls than boys (ref.) & & & & & & & 1.00 & \\
\hline $\begin{array}{l}\text { Equal numbers of surviving boys } \\
\text { and girls }\end{array}$ & & & & & & & 0.82 & * \\
\hline
\end{tabular}

* $\mathrm{p}<0.05$

** $\mathrm{p}<0.01$

n.a. not available

Source: Moyle (2015: Tables A7.11-7.19).

Table 7.18b Estimated (significant) effects (relative risks) of various characteristics on parity progression from a piecewise exponential hazard model, complete group: 1860/70, 1880 and 1890 marriage cohorts, Tasmania

\begin{tabular}{|c|c|c|c|c|c|c|c|c|c|}
\hline & \multicolumn{9}{|c|}{ Parity progression } \\
\hline & \multicolumn{2}{|c|}{$\begin{array}{c}5 \text { to } 6 \\
\text { Rel. risks }\end{array}$} & \multicolumn{2}{|c|}{$\begin{array}{c}6 \text { to } 7 \\
\text { Rel. risks }\end{array}$} & \multicolumn{2}{|c|}{$\begin{array}{c}7 \text { to } 8 \\
\text { Rel. risks }\end{array}$} & \multicolumn{2}{|c|}{$\begin{array}{c}8 \text { to } 9 \\
\text { Rel. risks }\end{array}$} & $\begin{array}{l}9 \text { to } 10 \\
\text { Rel. risks }\end{array}$ \\
\hline \multicolumn{10}{|l|}{ Mother's age at the birth } \\
\hline$<30$ years (ref.) & 1.00 & & 1.00 & & 1.00 & & 1.00 & & \\
\hline 30 to $<35$ years & 0.61 & $\star *$ & 0.81 & * & 0.53 & $\star \star$ & & & \\
\hline $35+$ years & 0.15 & ** & 0.29 & ** & 0.20 & $\star \star$ & 0.32 & ** & \\
\hline \multicolumn{10}{|l|}{ Mother's age at marriage } \\
\hline$<20$ years (ref.) & 1.00 & & 1.00 & & & & & & \\
\hline 20 to $<25$ years & 1.28 & ** & & & & & & & \\
\hline $25+$ years & 2.60 & ** & 1.42 & * & & & & & \\
\hline \multicolumn{10}{|l|}{ Age difference between couple } \\
\hline $\begin{array}{l}\text { Same age/husband up } \\
\text { to } 4 \text { years older (ref.) }\end{array}$ & & & 1.00 & & & & & & \\
\hline Husband 5+ years older & & & 0.83 & * & & & & & \\
\hline \multicolumn{10}{|l|}{ Marriage cohort } \\
\hline $1860 / 70$ cohorts (ref.) & 1.00 & & 1.00 & & 1.00 & & 1.00 & & \\
\hline 1880 cohort & 0.73 & ** & & & & & & & \\
\hline 1890 cohort & 0.68 & ** & 0.73 & ** & 0.72 & ** & 0.68 & $\star *$ & \\
\hline
\end{tabular}




\begin{tabular}{|c|c|c|c|c|c|c|c|c|c|}
\hline & \multicolumn{9}{|c|}{ Parity progression } \\
\hline & \multicolumn{2}{|c|}{$\begin{array}{l}5 \text { to } 6 \\
\text { Rel. risks }\end{array}$} & \multicolumn{2}{|c|}{$\begin{array}{c}6 \text { to } 7 \\
\text { Rel. risks }\end{array}$} & \multicolumn{2}{|c|}{$\begin{array}{c}7 \text { to } 8 \\
\text { Rel. risks }\end{array}$} & $\begin{array}{c}8 \text { to } 9 \\
\text { Rel. risks }\end{array}$ & \multicolumn{2}{|c|}{$\begin{array}{l}9 \text { to } 10 \\
\text { Rel. risks }\end{array}$} \\
\hline \multicolumn{10}{|l|}{ Socioeconomic status } \\
\hline White-collar (ref.) & & & 1.00 & & & & & & \\
\hline Farmers & & & 1.34 & * & & & & & \\
\hline \multicolumn{10}{|l|}{ Type of geographic location } \\
\hline $\begin{array}{l}\text { Urban area in Tasmania } \\
\text { (ref.) }\end{array}$ & & & & & 1.00 & & & & \\
\hline Rural area in Tasmania & & & & & 1.24 & * & & & \\
\hline \multicolumn{10}{|l|}{ Religion } \\
\hline Anglican (ref.) & & & & & 1.00 & & & 1.00 & \\
\hline Methodist & & & & & 0.76 & * & & 1.39 & * \\
\hline $\begin{array}{l}\text { Child dies as infant before } \\
\text { conception of another }\end{array}$ & $1.50 \times$ & * & $1.60 *$ & ** & 1.43 & * & & 1.65 & * \\
\hline Number of surviving children & $1.13 \times$ & * & & & 1.11 & * & & & \\
\hline
\end{tabular}

Source: Moyle (2015: Tables A7.11-7.19).

In summary, women giving birth at older ages had a significantly lower risk of having another birth at most parities. In contrast, women marrying at older ages had a significantly higher risk of having another birth at some low parities. Women in the 1890 cohort had a significantly lower risk of having another birth than women in the $1860 / 70$ cohorts at most parities, while women in the 1890 cohort had a significantly lower risk at parities four and five. Women with a child dying as an infant while they were not pregnant had a significantly higher risk of having another birth at most parities. Wives of farmers and unskilled workers had a significantly higher risk of having another birth than wives of white-collar workers at some low parities. Women living in a rural area of Tasmania had a significantly higher risk of having another birth than women in urban areas at some low to medium parities. 


\section{Summary}

Bivariate and multivariate analyses of the fertility decline for the complete group in the four Tasmanian marriage cohorts indicate when fertility started to decline and provide support for some of the theories of how and why fertility declined in the late 19th and early 20th centuries.

Fertility declined in Tasmania from the second half of the 1880s and the fall was well established during the 1890s. Fertility began to fall from the $1860 / 70$ cohorts to the 1880 cohort but there was a much larger fall from the 1880 to the 1890 cohorts. Compared with women in the $1860 / 70$ cohorts, women in the 1880 cohort had a significantly lower risk of having another birth at parities four and five while women in the 1890 cohort had a significantly lower risk of having another birth at almost all parities from parity two onwards. The timing of the fertility decline supports demographic transition theory, since this was a period of social and economic change and modernisation in Tasmania.

Analyses of stopping and spacing behaviours provide support for both demographic transition theory (adjustment) and diffusion theory (innovation). The fall in fertility in late 19th-century Tasmania was due primarily to the practice of stopping behaviour in the 1880 and 1890 cohorts, while the practice of spacing behaviour in the 1890 cohort also contributed to the fertility decline. In all marriage cohorts, some groups had longer birth intervals than others, suggesting these groups were deliberately spacing their births before the fertility decline. However, the extent of the spacing was small and this may have been counterbalanced by shorter birth intervals of couples marrying at later ages or those with large families, having little effect on overall fertility levels in the earliest cohorts. Changes in starting behaviour made a small contribution to the fertility decline, due to an increase in the age at marriage, but it is unlikely a change in the age at marriage was related to fertility preferences.

The practice of stopping and spacing behaviours varied by different family characteristics, lending support to some of the theories of why fertility declined at this time.

Socioeconomic status was significantly associated with both stopping and spacing, supporting both diffusion and economic theories of fertility decline. In every marriage cohort, white-collar workers were significantly more likely to stop childbearing than skilled workers, farmers and unskilled 
workers. This indicates that white-collar workers were controlling their fertility before the fertility decline. In the 1890 cohort, white-collar workers were also spacing their births, compared with farmers and unskilled workers, possibly for economic reasons.

Geographic location was also significantly associated with stopping and spacing behaviours, supporting theories of diffusion. In every marriage cohort, people living in urban areas were more likely to stop having children and more likely to space their births than people living in rural areas. This indicates that people in urban areas were controlling their fertility before the fertility decline.

The findings relating to religion provide mixed support for theories of secularisation. Although there were no significant differences between religious groups in stopping behaviour, there were some differences in spacing behaviour. Other Nonconformists were more likely to space their births than Anglicans in every marriage cohort, indicating they were deliberately spacing their births before the fertility decline. This may also support theories of diffusion, since Other NonconformistsCongregationalists/Independents and Baptists_may have had higher literacy than Anglicans because of their emphasis on reading the scriptures. Methodists had significantly shorter birth intervals than Anglicans in the 1880 marriage cohort, but this is difficult to explain. It is important to note that the measure of religion used here is a measure of religious affiliation, not of religiosity. It also measures religion at marriage only and some couples may have changed their religious affiliation during their childbearing years.

In Tasmania, the literacy levels of the husband and wife were not significantly associated with fertility control practices, providing no support for theories of diffusion or gender equity. However, the measure of literacy — whether the husband and wife signed the marriage registeris fairly weak.

The analyses of stopping and spacing behaviours do not support the 'replacement' or 'insurance' effects of infant and child mortality on fertility. Having a child die in infancy while a mother was not pregnant was not a significant determinant of stopping. However, the more infant and child deaths the family experienced, the more likely they were to stop 
childbearing. The number of surviving children also had no significant association with the time to the next birth, indicating that couples were not adjusting their birth spacing in relation to deaths of infants or children.

The analysis of spacing behaviour supports the 'physiological' relationship between infant mortality and fertility. Having a child die as an infant when the woman was not pregnant significantly reduced the time to the next birth. This was because, with the death of an infant, the woman stopped breastfeeding and started to ovulate. The survival analysis of parity progression shows that women who had a child die as an infant had a significantly higher risk of having another birth than other women at most parities, but this may reflect the length of time to the next birth rather than having another birth. 
This text is taken from Australia's Fertility Transition: A study of 19th-century Tasmania, by Helen Moyle, published 2020 by ANU Press, The Australian National University, Canberra, Australia. 